University of Nebraska - Lincoln

DigitalCommons@University of Nebraska - Lincoln

Faculty Publications, Department of Psychology

Psychology, Department of

November 2000

\title{
Nicotine enhances acquisition of a T-maze visual discrimination: assessment of individual differences
}

\author{
J. Besheer \\ University of Nebraska-Lincoln
}

Rick A. Bevins

University of Nebraska-Lincoln, rbevins1@unl.edu

Follow this and additional works at: https://digitalcommons.unl.edu/psychfacpub

Part of the Psychiatry and Psychology Commons

Besheer, J. and Bevins, Rick A., "Nicotine enhances acquisition of a T-maze visual discrimination: assessment of individual differences" (2000). Faculty Publications, Department of Psychology. 40. https://digitalcommons.unl.edu/psychfacpub/40

This Article is brought to you for free and open access by the Psychology, Department of at DigitalCommons@University of Nebraska - Lincoln. It has been accepted for inclusion in Faculty Publications, Department of Psychology by an authorized administrator of DigitalCommons@University of Nebraska - Lincoln. 
Besheer J \& Bevins RA (2000) Nicotine enhances acquisition of a T-maze visual discrimination: Assessment of individual differences. From Behavioural Pharmacology, 11, 613-620. Published by Lippincott Williams \& Wilkins; copyright (c) 2000 Lippincott Williams \& Wilkins. Used by permission. 


\title{
Nicotine enhances acquisition of a T-maze visual discrimination: assessment of individual differences
}

\author{
J. Besheer and R.A. Bevins
}

Department of Psychology, University of Nebraska-Lincoln, Lincoln, USA

Correspondence to Rick A. Bevins, Department of Psychology, Burnett Hall, University of Nebraska-Lincoln, Lincoln, NE 68588-0308, USA. E-mail: rbevins1@unl.edu

Received 28 March 2000; accepted as revised 25 August 2000

In the present report, rats' performance was assessed in five tasks designed to measure behavioral response to different novel stimuli under different experimental situations. Daily nicotine treatment $(0,0.3 \mathrm{or} 1.0 \mathrm{mg} / \mathrm{kg}) \mathrm{began}$ after the conclusion of the behavioral tasks and continued throughout the experiment. Training of a T-maze visual discrimination task commenced after 11 days of nicotine pretreatment. As a group, rats treated with the higher dose of nicotine $(1.0 \mathrm{mg} / \mathrm{kg}$ ) made fewer errors to acquire the initial T-maze discrimination than saline-treated controls. Activity induced by an inescapable novel environment (i.e. first behavioral screen) was positively correlated with the number of errors to acquire the initial discrimination in the T-maze for the two nicotine-treated groups $(0.3 \mathrm{and} 1.0 \mathrm{mg} / \mathrm{kg})$. To examine this positive correlation further, a median split analysis was conducted on the novelty-induced activity for each group. Nicotine, especially the high dose $(1.0 \mathrm{mg} / \mathrm{kg})$, enhanced performance in rats that were Iess active in the inescapable novel environment. Nicotine treatment did not affect the performance of rats that were more active in that environment. After the initial visual discrimination was acquired, the reverse discrimination was trained. Nicotine treatment did not affect performance; the number of errors to acquire the reversal for nicotine- and saline-treated rats did not differ. Overall a nicotine-induced improvement in performance is demonstrated which can be predicted by a rat's reactivity to environmental novelty. 92000 Lippincott Williams \& Wilkins.

Keywords: acetylcholine, cholinergic, learning, memory, novelty, rat

\section{INTRODUCTION}

An animal's reactivity to a novel environment has been shown to predict later sensitivity to drugs of abuse. Reactivity to novelty is typically measured by a rat's locomotor activity in an inescapable novel environment (Piazza et al., 1989; Rougé-Pont et al., 1993; Hooks et al., 1994; Bevins et al., 1997). Commonly, a median split is conducted on the noveltyinduced activity, with those rats displaying greater activity than the median being classified as high responders (HRs), and rats displaying less activity than the median classified as low responders (LRs). Individual differences research has reported predictive relations between reactivity to environmental novelty and sensitivity to the behavioral effects of amphetamine (e.g. Piazza et al., 1989; Bevins et al., 1997), cocaine (e.g. Hooks et al., 1992; Grimm and See, 1997), and ethanol (e.g. Gingras and Cools, 1995, 1996),

The present report examines whether rats' response to novelty could predict subsequent learning of a visual discrimination task in saline- and/or chronic nicotine-treated rats. Performance after nicotine (a nicotinic acetylcholine receptor agonist) treatment was examined because of the recent interest in the effects of nicotine on learning and performance. For example, nicotine treatment can improve rats' performance in a radial-arm maze (Levin et al., 1990, 1996a, 1996b), a Morris water maze (Abdulla et $a l ., 1993$ ) and a five-choice serial reaction time task (Mirza and Stolerman, 1998). In each task, variability in performance existed in nicotinetreated groups as well as in the controls. Unfortunately, these individual differences have not been examined closely. Research has yet to assess whether nicotine-induced changes in performance can be predicted by behavioral screens (i.e. exposure to an inescapable novel environment) that have been shown to predict sensitivity to other drugs of abuse (e.g. amphetamine and cocaine).

The present work had two major goals. The first was to assess whether nicotine treatment would en- 
hance the acquisition or the reversal of a visual discrimination. The second was to determine whether there was a predictive relationship between T-maze performance and the five behavioral tasks/screens designed to measure sensitivity to different 'types' of novelty (e.g. forced versus free-choice exposure), and whether this relationship would shift with nicotine treatment.

These behavioral screens included two exposures to an inescapable environment (the environment was novel on the first exposure, and the second exposure occurred 9 days later). The first exposure served as a measure of reactivity to environmental novelty. As described earlier, novelty-induced activity has been used widely to predict individual differences in sensitivity to drugs of abuse. Two further screens included novel-object preference tests on an elevated platform and in an enclosed environment. In contrast to the inescapable novel environment, this preparation measures response to novelty in a free-choice procedure (Besheer et al., 1999). Interestingly, preference for the novel object has been correlated positively with hippocampal choline acetyltransferase levels (Willig et al., 1992). From our perspective this correlation is of interest, given that we are examining the effects of nicotine, a cholinergic receptor agonist. Further, screens that allow exposure to novelty in a free-choice procedure have been shown to predict amphetamine effects (e.g. Klebaur and Bardo, 1999). The final behavioral screen assessed sensitivity to a novel tastant (i.e. saccharin). Saccharin intake has been shown to be correlated positively with ethanol consumption in rats (Koros et al., 1998).

\section{METHOD}

\section{Subjects}

Thirty-two naïve male Sprague-Dawley rats, weighing 250-275 g on arrival from Harlan Industries (Indianapolis, IN, USA) were used in this experiment. Rats were housed individually in plastic tubs lined with aspen wood chips. The colony room was maintained on a 12-hour light: dark cycle; the experiment was conducted during the light portion of this cycle.

\section{Apparatus}

Activity was measured in one of eight circular chambers made from white PVC pipe. The inside diameter of the chamber was $30.5 \mathrm{~cm}$; the top edge of the chamber was $45 \mathrm{~cm}$ from the wire-mesh floor. The chamber was divided into quadrants by two infrared beams that were mounted $4 \mathrm{~cm}$ above the mesh floor.

The elevated platform used in the novel-object preference screen was a stainless-steel tray $(57 \times$ $65.5 \mathrm{~cm}(1 \times \mathrm{w})$, with a $3-\mathrm{cm}$ raised edge), which was elevated $70 \mathrm{~cm}$ from the ground using a small table. Two similar three-compartment chambers were used in a second novel-object preference screen. The dimensions of the two end compartments were $31 \times$ $24 \times 45.5(1 \times \mathrm{w} \times \mathrm{h}) \mathrm{cm}$. One end compartment had white walls, a wire-mesh floor, and pine wood chips lining the litter tray. The other end compartment had black walls, a rod floor, and newspaper lining the litter tray. The smaller center compartment ( 15 $\times 24 \times 45.5 \mathrm{~cm}$ ) had gray walls and an aluminum floor. The floors were $19.5 \mathrm{~cm}$ above the litter trays. During testing the inside walls of each end compartment were raised $11 \mathrm{~cm}$.

Objects used in the novel-object preference screen on the elevated platform were a green scouring pad $(9 \mathrm{~cm}$ diameter) and a peach paint roller $(7.5 \mathrm{~cm}$ long, $4 \mathrm{~cm}$ diameter). Objects used in the novelobject preference screen in the enclosed environment were a sponge $(10 \times 7 \times 3 \mathrm{~cm})$ and a white PVC pipe ( $15 \mathrm{~cm}$ long, $5 \mathrm{~cm}$ opening). For each screen, which object served as the novel object was counterbalanced as much as allowed by the sample size.

The T-maze was constructed from wood and painted gray. A start box $(28.5 \times 18 \times 37.5 \mathrm{~cm})$ was attached to one end of the stem. The door of the start box, when raised, allowed the rat to enter the stem of the maze through an opening $10.5 \mathrm{~cm}$ wide and $15.5 \mathrm{~cm}$ high. The stem $(110 \mathrm{~cm}$ long) and the arms $(53 \mathrm{~cm}$ long) were approximately $11 \mathrm{~cm}$ wide and the walls were $28 \mathrm{~cm}$ high. The dimensions of the maze were adapted from those given in previous reports (Simon et al., 1986; Wirtshafter and Asin, 1986). A food well, $0.7 \mathrm{~cm}$ deep with a diameter of $2 \mathrm{~cm}$, was located at the end of each arm. Post Fruity Pebbles ${ }^{\circledR}$ cereal served as the reinforcer. To control for the scent of the Fruity Pebbles, a small amount of the cereal was wrapped in gauze and attached to the outside top of the end of each arm. A mirror was attached to the maze along the length of the arms and angled so that the experimenter could see the rat in the stem and arms of the maze while standing behind the start box.

\section{Novelty behavioral screens}

\section{Inescapable novel environment}

Reactivity to an inescapable novel environment was measured on Day 1. Rats were placed in the circular chambers and activity was monitored for $1 \mathrm{~h}$. The number of beam breaks in this time served as the measure of novelty-induced activity. 
Novel-object preference (elevated platform)

A novel-object preference test occurred on the following day. Rats were placed on an elevated platform for $5 \mathrm{~min}$. Two identical 'sample' objects were located in the two corners furthest from the placement of the rat. One hour later, rats were returned to the platform for $2 \mathrm{~min}$. One of the previously experienced sample objects was replaced by a novel object. Time spent interacting with objects was measured later from videotape. Rats did not participate in any behavioral screens on Days 3 to 5 .

\section{Saccharin consumption}

On Day 6, the homecage water bottles were filled with $150 \mathrm{ml}$ of a $0.1 \%$ saccharin solution. Saccharin consumption was measured $24 \mathrm{~h}$ later (Day 7), Rats remained in the homecage on the following day and tap water was available in the bottles for the remainder of the experiment.

\section{Novel-object preference (enclosed environment)}

A novel-object preference test occurred on Day 9. This test was conducted in the three-compartment chamber (i.e. enclosed environment). Each rat was confined to an end compartment for $5 \mathrm{~min}$. The sample object was placed in the end compartment for the final $1.5 \mathrm{~min}$ of the 5 -min confinement. The rat was then removed and immediately confined to the other end compartment for the same amount of time. Again, the sample object was placed for the final $1.5 \mathrm{~min}$ of the confinement. The novel-object test followed $1 \mathrm{~h}$ later. During this test, each rat was placed in the center gray compartment and allowed free access to both end compartments for $2 \mathrm{~min}$. The previously experienced sample object was located in one end compartment and a novel object was located in the other end compartment Time spent interacting with objects was measured later from videotape.

\section{Inescapable environment}

On the final day of the behavioral screens (Day 10), each rat was returned to the chamber experienced on Day 1 and locomotor activity was recorded for $1 \mathrm{~h}$.

\section{T-maze visual discrimination task}

\section{Food restriction}

Immediately after the final behavioral screen, rats' weights were gradually decreased to $85 \%$ of their free-feeding weight (i.e. target weight) across 1 week. Rats were fed a specific amount of food once daily. This amount was determined for each rat based on its weight for that day. Food restriction continued for the duration of the experiment. The target weight was increased by $2 \mathrm{~g}$ every 27 days to accommodate a normal growth curve.

\section{Nicotine pretreatment}

After 1 week of food restriction nicotine pretreatment began. Rats were assigned randomly to the 0 (saline), 0.3 or $1.0 \mathrm{mg} / \mathrm{kg}$ nicotine group $(n=10-11$ per group). During this pretreatment phase, rats received a subcutaneous (s.c.) injection of the assigned solution once daily for 11 days. This daily injection protocol continued throughout the experiment (see later).

\section{T-maze shaping}

On Days 7 and 8 of nicotine pretreatment, rats received access to a small amount of Fruity Pebbles in the homecage. Shaping began on Day 9 of nicotine pretreatment. For the remainder of the experiment, rats were injected with the assigned solution $15 \mathrm{~min}$ before placement in the T-maze. Each rat was placed in the start box for $10 \mathrm{~s}$ before the door was raised. Once the rat entered the maze the door was closed. The stem, arms and food wells of the maze were baited with Fruity Pebbles. The rat remained in the maze until all cereal was consumed. The same protocol was used on the second and third day of shaping (Days 10 and 11 of nicotine pretreatment) except only the arms and food wells were baited on the second day; on the third day only the food wells contained cereal.

\section{T-maze acquisition training}

A removable insert was placed in each of the arm of the maze for the rest of the experiment. Thes inserts were black on one side and white on th other side. For each group, food was only available in the black arm of the maze. Rats received four trials each day, with about $4 \mathrm{~min}$ between each trial. Injection of the assigned solution occurred $15 \mathrm{~min}$ prior to the first trial each day. The position of the black arm was determined randomly with the constraint that the arm appeared on the right side and the left side twice each day. The maze was wiped thoroughly with isopropyl alcohol between each rat to eliminate odor cues. Latency to make a correct arm choice after the rat left the start box was recorded. An arm choice was defined as the two front paws of the rat crossing a marker (on the outside of the maze) drawn three-quarters of the way into the arm. If an incorrect arm choice occurred (i.e. entry into white arm), the rat was con- 
fined to that arm for $10 \mathrm{~s}$. When a correct arm choice occurred, the rat was removed from the maze after all the cereal was consumed.

The numbers of incorrect and correct arm choices were recorded each day. Criteria for acquisition of the discrimination were set as 1 incorrect arm choice in 4 days (i.e. 1 error in 16 trials) and a rat total of no more than 50 errors (cf. Peternel et al., 1988). Once the discrimination was acquired, reversal training began on the following day. One rat in the $0.3 \mathrm{mg} / \mathrm{kg}$ group failed to reach the acquisition criterion and its data were excluded from any analyses. Further, one rat in the $1.0 \mathrm{mg} / \mathrm{kg}$ group repeatedly jumped out of the maze and its data were not included in any analyses.

\section{T-maze reversal training}

The procedures and the acquisition criterion for this phase of training were identical to acquisition, except food was only available in the white arm and no limit was set for the number of errors to reach criterion. Again, rats were injected with the assigned solution $15 \mathrm{~min}$ prior to the first trial each day.

\section{Drugs}

(-)-Nicotine hydrogen tartrate (Sigma, St. Louis, MO, USA) was mixed in saline and brought to a $\mathrm{pH}$ of $7.0 \pm 0.1$ with a dilute sodium hydroxide solution. Injections were subcutaneous (s.c.) at a volume of 1 $\mathrm{ml} / \mathrm{kg}$. Calculation of the doses used were based on the salt form of the drug.

\section{Behavioral observations and data analyses}

Object interaction was defined as any directed contact with the object. This definition precluded behaviors such as backing into the object or bumping the tail against the object (see Bevins et al., 1997; Besheer et al., 1999). A rater naive to the conditions received by the rats assessed the reliability of the observations of the primary rater (J. Besheer). The Spearman's rho $\left(\rho_{\mathrm{s}}\right)$ correlation between 28 independent observations of object interaction during the novel-object test was high [ $\left.\rho_{\mathrm{s}}=0.925, P<0.001\right]$.

Due to the small sample size and the heterogeneity of variance, nonparametric statistics were used to analyze the data. For the novel-object preference screens, a difference score was calculated by subtracting the time interacting with the sample object from the time interacting with the novel object. Thus, a value significantly greater than $0 \mathrm{~s}$, as assessed by the Wilcoxon Signed Rank test, indicates that the rat was spending more time with the novel object. Spearman's rho correlations were used to examine relations between the different behavioral screens and T-maze performance. Due to experimenter error and a computer error, saccharin intake for one rat and locomotor activity during the second exposure to the inescapable environment for three rats, respectively, were not recorded. Analyses of these screens did not include these rats. In the novel-object screen in the enclosed environment, one rat did not interact with either object during the novel-object test and was not included in the analysis on this screen. Mann-Whitney tests were used to extract group differences in T-maze performance. The significance level for all analyses was set at $P \leq 0.05$ unless otherwise noted.

\section{RESULTS}

Behavioral screens

As the rats did not receive differential nicotine treatment until the conclusion of the behavioral screens, these data were pooled into one group $(n=30)$. The means (SEM) for each screen were as follows: activity (i.e. number of beam breaks) during the first exposure to the inescapable environment, 1292 (103); and during the second exposure, 1281 (92); difference score (in seconds) during the novelobject preference test on the elevated platform, 7.96 (1.28), and in the enclosed environment, 5.95 (1.54); saccharin intake (in milliliters) 72.4 (4.3). Rats spent significantly more time interacting with the novel object during both novel-object tests, as revealed by a median difference score significantly above $0 \mathrm{~s}$, $P \mathrm{~s} \leq 0.001$. To examine whether any relations existed between the behavioral screens, we correlated performance on each of the screens. A significant correlation revealed that the more active the rats were in the initial exposure to the inescapable environment, the more active they were during the second exposure to the same environment $\left[\rho_{\mathrm{s}}=0.476\right.$, $P<0.02]$. No other correlations were significant [largest $\rho_{\mathrm{s}}=0.236, P>0.2$ ].

\section{T-maze performance}

The overall mean number of errors (SEM) to acquire the initial discrimination for each group were as follows: saline, 24.50 (3.61); $0.3 \mathrm{mg} / \mathrm{kg}$ nicotine, 20.20 (3.94); and $1.0 \mathrm{mg} / \mathrm{kg}$ nicotine, $13.40(2.85)$. Because we made multiple comparisons to the saline group, the significance level of this test was set at $P$ $\leq 0.025$ ( $\alpha$ level/number of comparisons). For the acquisition of the initial discrimination, there was no difference in the number of errors to reach criteria between the saline-treated and $0.3 \mathrm{mg} / \mathrm{kg}$ nicotinetreated group [U $=39.00$, NS]. However, rats treated with $1.0 \mathrm{mg} / \mathrm{kg}$ nicotine made significantly fewer errors than the saline control $[\mathrm{U}=19.50, P<0.02]$. 
During reversal training, the number of errors to acquire the reverse discrimination in the $0.3 \mathrm{mg} / \mathrm{kg}$ nicotine group $[\mathrm{U}=35.5, \mathrm{NS}]$, and the $1.0 \mathrm{mg} / \mathrm{kg}$ group $[U=35.0, N S]$, did not differ from the salinetreated group. The mean number of errors (SEM) to acquire the reverse discrimination were as follows: saline, $121.90(12.36) ; 0.3 \mathrm{mg} / \mathrm{kg}$ nicotine, 105.10 (10.84); and $1.0 \mathrm{mg} / \mathrm{kg}$ nicotine, $96.90(13.09)$.

\section{Behavioral screens and T-maze performance}

There was a significant positive correlation between the initial exposure to the inescapable novel environment and subsequent acquisition of the initial T-maze discrimination, but only for the nicotinetreated rats (see Table 1). Thus, for both nicotinetreated groups, rats that were less reactive to the inescapable novel environment made fewer errors in acquiring the initial discrimination (i.e. faster acquisition). For the $0.3 \mathrm{mg} / \mathrm{kg}$ nicotine group, there was also a significant positive correlation between exposure to the inescapable novel environment and the number of errors to acquire the reverse discrimination. For this moderate dose of nicotine, activity during the second exposure to the inescapable environment also correlated with the number of errors to acquire the initial and reverse discrimination. Finally, there was a significant positive correlation between the number of errors to acquire the initial discrimination and the number of errors to acquire the reverse discrimination for the $0.3 \mathrm{mg} / \mathrm{kg}$ nicotine group.

A median split analysis revealed that the high dose of nicotine $(1.0 \mathrm{mg} / \mathrm{kg}$ ) specifically enhanced performance of rats classified as low responders (LRs) in activity during exposure to the inescapable novel environment (i.e. those rats displaying activity below the median after conducting a median split; cf. Piazza et al., 1989; Hooks et al., 1992; Bevins et al., 1997). Figure 1A shows the locomotor activity profile for the LRs and HRs of each group after the median split. Figure $1 \mathrm{~B}$ shows the mean number of errors to acquire the initial discrimination for LRs and HRs in each group. The number of errors for the LRs in the $0.3 \mathrm{mg} / \mathrm{kg}$ nicotine group did not differ significantly from the LRs in the saline-treated group $[\mathrm{U}=4.00, P=0.095]$. However, $\mathrm{LRs}$ in the $1.0 \mathrm{mg} / \mathrm{kg}$ nicotine group made significantly fewer errors to acquire the initial discrimination (i.e. acquired the task faster) than the LRs in the salinetreated group $[U=1.00, P<0.02]$. In contrast, rats classified as high responders (HRs; i.e. novelty-induced activity above the median) at either dose of nicotine did not differ from the saline-treated HRs. Together, these results show that nicotine differentially affected performance of LRs and HRs: specifically, performance was only enhanced in the LRs.

Finally, to assess whether LRs and HRs differed in general locomotor activity in the T-maze, we examined the latency to make a correct arm choice. For each rat, an average latency to make a correct arm choice on the first day of T-maze visual discrimination training (i.e. the first day after the 3 days of shaping) was calculated. No significant differences in latency were found between LRs and HRs for any group $[P \mathrm{~s} \geq 0.3]$. Thus, differences in general locomotor activity in the T-maze are unlikely to account for the differential performance of LRs and HRs in acquiring the initial T-maze discrimination.

\section{DISCUSSION}

Previous research has shown that individual differences in amphetamine self-administration (Piazza et al., 1989), cocaine self-administration (Grimm and See, 1997) and ethanol consumption (Gingras and Cools, 1995) can be predicted by an animal's reactivity to a novel environment. The present investigation sought to examine whether performance on a variety

TABLE 1. Correlations between behavioral screens and T-maze performance

\begin{tabular}{|c|c|c|c|c|c|c|}
\hline \multirow[b]{2}{*}{ Screen } & \multicolumn{2}{|c|}{ Saline } & \multicolumn{2}{|c|}{$0.3 \mathrm{mg} / \mathrm{kg}$} & \multicolumn{2}{|c|}{$1.0 \mathrm{mg} / \mathrm{kg}$} \\
\hline & Acquisition & Reversal & Acquisition & Reversal & Acquisition & Reversal \\
\hline $\begin{array}{l}\text { Inescl } \\
\text { DiffSc(ele) } \\
\text { Saclnt } \\
\text { DiffSc(enc) } \\
\text { Inescll } \\
\text { Acquisition }\end{array}$ & $\begin{array}{l}-0.042 \\
-0.224 \\
-0.494 \\
-0.433 \\
-0.060\end{array}$ & $\begin{array}{r}0.200 \\
0.370 \\
0.140 \\
-0.150 \\
0.108 \\
0.515\end{array}$ & $\begin{array}{c}0.854^{* *} \\
-0.085 \\
-0.156 \\
-0.012 \\
0.689^{*}\end{array}$ & $\begin{array}{c}0.636^{*} \\
-0.552 \\
-0.359 \\
0.345 \\
0.733^{*} \\
0.738^{*}\end{array}$ & $\begin{array}{c}0.869^{* *} \\
-0.426 \\
-0.026 \\
-0.140 \\
-0.158\end{array}$ & $\begin{array}{r}0.309 \\
0.067 \\
-0.390 \\
0.248 \\
0.224 \\
0.620\end{array}$ \\
\hline
\end{tabular}

Abbreviations: Inescl, activity during the initial exposure to the inescapable environment; DiffSc(ele), difference score during the novel-object preference test (elevated platform); Sacint, total saccharin intake; DiffSc(enc), difference score during the novel-object preference test (enclosed environment); Inescil, activity during the second exposure to the inescapable environment; Acquisition, number of errors to acquire the initial T-maze visual discrimination; Reversal, number of errors to acquire the T-maze reverse discrimination.

* $P \leq 0.05 ; * * P \leq 0.01$. 

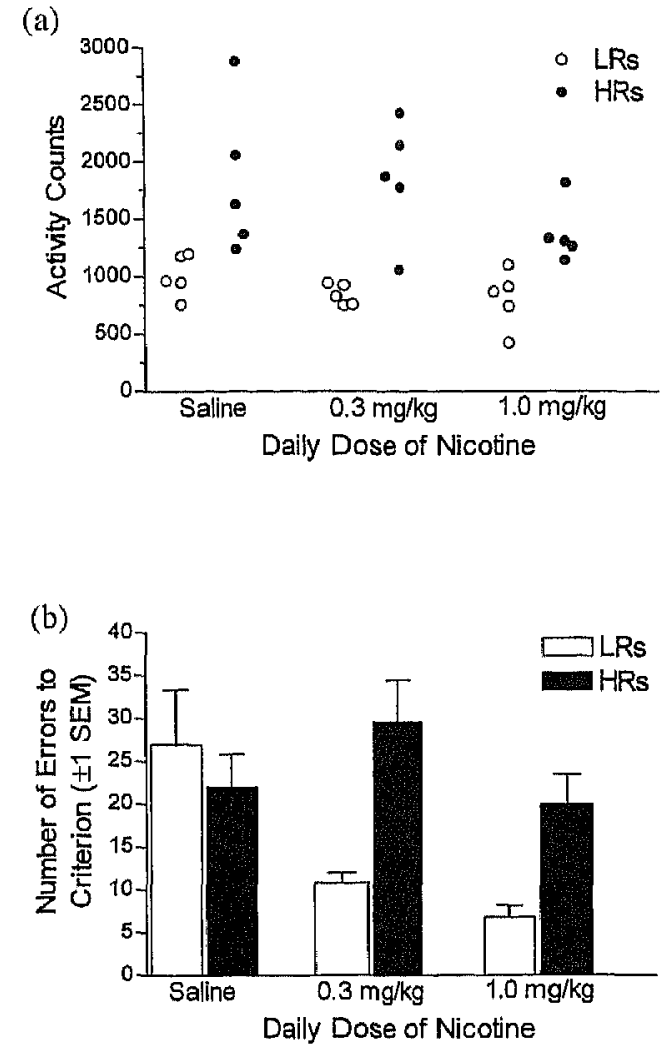

FIGURE 1. Panel A shows the locomotor activity during the initial exposure to the inescapable novel environment for each group after the median split. The low responders (LRs) are those rats displaying aotivity below the median. The high responders (HRs) are those rats displaying activity above the median. Panel $B$ shows the mean number of errors $( \pm S E M)$ to acquire the initial visual discrimination in the T-maze for the LRs and the HRs of each group.

of behavioral screens designed to assess sensitivity to different 'types' of novelty (see later) could predict nicotine-induced performance in a visual discrimination task. Indeed, for both nicotine-treated groups $(0.3$ and $1.0 \mathrm{mg} / \mathrm{kg})$, initial acquisition performance in the T-maze was predicted by reactivity to the inescapable novel environment. Rats that were less reactive to the novel environment made fewer errors to acquire the initial T-maze discrimination than rats that were more reactive to the novel environment. This correlation was not present in salinetreated rats.

In the individual differences literature, differential and predictable behavioral responses to the drug being studied appear to emerge more readily when moderate doses are administered (e.g. Piazza et al., 1989; Bevins et al., 1997). This suggestion is consistent with the findings of the present experiment. At the lower dose of nicotine $(0.3 \mathrm{mg} / \mathrm{kg})$ more consis- tent correlations between the inescapable environment and T-maze performance were observed than at the higher dose of nicotine $(1.0 \mathrm{mg} / \mathrm{kg})$. For example, reactivity to the inescapable novel environment predicted initial acquisition of the T-maze visual discrimination and acquisition of the reverse discrimination. However, reactivity to the inescapable novel environment did not predict performance during the reversal phase for the $1.0 \mathrm{mg} / \mathrm{kg}$ nicotine group. Reactivity to the second exposure of the inescapable environment also predicted performance for the initial and reverse discrimination only in the $0.3 \mathrm{mg} / \mathrm{kg}$ nicotine group. Interestingly, the number of errors to acquire the initial discrimination was positively correlated with the number of errors to acquire the reverse discrimination in the $0.3 \mathrm{mg} / \mathrm{kg}$ nicotine group; this correlation approached significance in the $1.0 \mathrm{mg} / \mathrm{kg}$ group $(P=$ $0.056)$. This outcome suggests that chronic nicotine treatment may influence similar neural mechanisms during acquisition and reversal training. In addition, when the number of errors to acquire the initial discrimination for the LRs of both nicotine-treated groups were compared to the number of errors in the LRs of the saline-treated group, a significant difference emerged only at the highest nicotine dose (i.e. $1.0 \mathrm{mg} / \mathrm{kg}$ ). This result is consistent with the idea that moderate drug doses produce greater individual differences (e.g. variability) than higher drug doses. Thus, at the moderate dose, the increased variability combined with the small sample size most likely contributed to the lack of a significant difference in the number of errors between the LRs of the $0.3 \mathrm{mg} / \mathrm{kg}$ nicotine group and the LRs of the saline-treated group.

In the widely cited report by Piazza et al. (1989), rats that were classified as HRs to environmental novelty displayed greater locomotor activity than LRs after an amphetamine injection. In a separate experiment, amphetamine self-administration was acquired faster by HRs than LRs. Since the publication of that report, researchers have examined the neurochemical correlates of HRs and LRs in response to an inescapable novel environment (e.g. Piazza et al., 1991; Rougé-Pont et al., 1993; Saigusa et al., 1999), and others have examined the behavioral correlates (e.g. Gingras and Cools, 1995; Bevins et al., 1997; Grimm and See, 1997). Thus, out of tradition, activity induced by an inescapable novel environment has become the most widely used behavioral screen for assessing individual differences in sensitivity to drugs of abuse.

In the present report, the behavioral screens were designed to assess reactivity to different 'types' of 
novelty. The two novel-object preference tests allowed rats free access to novelty. Specifically, rats had a choice to interact with a novel or a familiar object. In contrast, exposure to the inescapable environment forced rats into a novel environment. The saccharin consumption screen was similar to the inescapable environment screen in that rats were not allowed a choice between novel and familiar; however, the saccharin consumption screen differed from the inescapable environment screen in that rats could sample the novel tastant and choose not to consume the fluid. Interestingly, only the forced exposure to novelty (inescapable novel environment) predicted T-maze performance. Others have reported a predictive relation between a free-choice novelty screen and the effects of amphetamine (e.g. Klebaur and Bardo, 1999). At present, it is unclear when free-choice versus forced-choice novelty tasks will predict the effects of abused drugs, including nicotine. This issue will require further research with different tasks and drug effects. Regardless, in this report, forced exposure to a novel environment predicted a nicotine-induced alteration in learning, and has reliably predicted performance in other laboratories. This consistency suggests that further investigation of the behavioral and neural processes mediating response to a novel environment may reveal much about the processes mediating drug effects.

Overall, nicotine influenced performance in a $\mathrm{T}$ maze visual discrimination task. Rats treated with the higher dose of nicotine $(1.0 \mathrm{mg} / \mathrm{kg})$ learned the initial visual discrimination faster (i.e. fewer errors) than saline-treated rats. This finding is consistent with previous work reporting enhanced performance with nicotine treatment (Levin et al., 1990, 1996a, 1996b; Abdulla et al., 1993; Mirza and Stolerman, 1998). However, nicotine treatment has also been shown to impair or have no effect on performance (Dunnett and Martel, 1990; Levin et al., 1997; reviewed by Levin and Simon, 1998). Interestingly, the demands of the tasks used by Dunnett and Martel (1990) and Levin et al. (1997) allow for proactive interference. As discussed in both reports, nicotine may enhance proactive interference, thus preventing a nicotine-induced improvement in performance. In contrast, proactive interference was not a factor in the radial-arm maze tasks used by Levin et al. (1990, 1996a, 1996b) in which nicotine-induced improvements are consistently reported, nor in the visual discrimination task used in the present report. Thus, while this report contributes to the literature a different behavioral task in which nicotine-induced enhanced performance can be observed, the conditions under which nicotine can alter performance must be investigated further. In addition, we have examined the individual differences that contribute to nicotineinduced enhanced performance. Specifically, this report has uncovered a predictive relationship between reactivity to environmental novelty and subsequent nicotine-induced performance.

\section{Acknowledgements}

This research was supported by funds from NIH (DA11893), NSF (OSR9255225) and Nebraska Department of Health. We thank Kevin Pang and Matthew Palmatier for their thoughtful comments on an earlier version of this manuscript. We are grateful to Katherine Pickett for conducting the independent observations used to assess interobserver reliability, Sarah Eurek for her assistance in conducting the experiment, Calvin Garbin for his help in constructing the T-maze, and Roger Dooley for constructing the automated locomotor system.

\section{REFERENCES}

Abdulla FA, Calaminici M-R, Stephenson JD, Sinden JD (1993), Chronic treatments with cholinoceptor drugs influence spatial learning in rats. Psychophamnacology 111:508-511.

Besheer J, Jensen HC, Bevins RA (1999). Dopamine antagonism in a novel-object recognition and a novel-object place conditioning preparation with rats. Behat Brain Res 103:35-44.

Bevins RA, Klebaur JE, Bardo MT (1997). Individual differences in response to novelty, amphetamine-induced activity and drug discrimination in rats. Behav Pharnacol 8:113-123.

Dunnett SB, Martel FL (1990). Proactive interference effects on short-term memory in rats: 1 . Basic parameters and drug effects. Behav Neurosci 104:655-665.

Gingras MA, Cools AR (1995). Differential ethanol intake in high and low responders to novelty. Behav Pharmacol 6:718-723.

Gingras MA, Cools AR (1996). Analysis of the biphasic loconotor response to ethanol in high and low responders to novelty: a study in Nijmegen Wistar rats. Psychopharmacology 125:258-264.

Grimm JW, See RE (1997). Cocaine self-administration in ovariectomized rats is predicted by response to novelty, attenuated by $17-\beta$ estradiol, and associated with abnormal vaginal cytology. Physiol Behav 61:755-761.

Hooks MS, Jones GH, Liem BJ, Justice JB Jr (1992). Sensitizaltion and individual differences to IP amphetamine, cocaine, or caffeine following repeated intracranial amphetamine infusions. Pharmacol Biochem Behav 43:815-823.

Hooks MS, Juncos JL, Justice JB Jr, Meiergerd SM, Povlock SL, Schenk JO, Kalivas PW (1994). Individual locomotor response to novelty predicts selective alterations in $D_{1}$ and $D_{2}$ receptors and mRNAs. $J$ Neurosci 14:6144-6152.

Klebaur IE, Bardo MT (1999). Individual differences in novelty seeking on the playground maze predict amphetamine conditioned place preference. Pharmacol Biochem Behat 63:131-136.

Koros E, Piasecki J, Kostowski W, Bienkowski P (1998). Saccharin drinking rather than open field behaviour predicts initial ethanol acceptance in Wistar rats. Alcohol Alcohol 33:131-140.

Levin ED, Simon BB (1998). Nicotinic acetylcholine involvement in cognitive function in animals. Psychophamacology 138:217-230.

Behavioural Pharmacology 2000, Vol 11 Nos $7 \& 8$ 
Levin ED, Lee C, Rose JE, Reyes A, Ellison G, Jarvik M, Gritz E (1990). Chronic nicotine and withdrawal effects on radial-arm maze performance in rats. Behau Neural Bio 53:269-276.

Levin ED, Kim P, Meray R (1996). Chronic nicotine working and reference memory effects in the 16-arm radial maze: interactions with $\mathrm{D}_{1}$ agonist and antagonist drugs. Psychopharmacology 127:25-30.

Levin ED, Christopher NC, Briggs SJ, Auman JT (1996). Chronic nicotine-induced improvement of spatial working memory and $\mathrm{D}_{2}$ dopamine effects in rats. Drug Develop Res 39:29-35.

Levin ED, Christopher NC, Briggs SJ (1997). Chronic nicotine agonist and antagonist effects on T-maze alternation. Physiol Behav 61:863-866.

Mirza NR, Stolerman IP (1998). Nicotine enhances sustained attention in the rat under specific task conditions. Psychopharmacology 138:266-274.

Peternel A, Hughey D, Wenk D, Olton D (1988). Basal forebrain and memory: neurotoxic lesions impair serial reversals of a spatial discrimination. Psychobiology 16:54-58,

Piazza PV, Deminière J-M, Le Moal M, Simon H (1989). Factors that predict individual vulnerability to amphetamine selfadministration. Science 245:1511-1513.

Piazza PV, Maccari S, Deminière I, Le Moal M, Mormede P,
Simon H (1991). Corticosterone levels determine individual vulnerability to amphetamine self-administration. Proc Natl Acad Sci USA 88:2088-2092.

Rogué-Pont F, Piazza PV, Kharouby M, Le Moal M, Simon H (1993). Higher and longer stress-induced increase in dopamine concentrations in the nucleus accumbens of animals predisposed to amphetamine self-administration. A microdialysis study. Brain Res 602:169-174.

Saigusa T, Tuinstra T, Koshikawa N, Cools AR (1999). High and low responders to novelty: effects of a catecholamine synthesis inhibitor on novelty-induced changes in behaviour and release of accumbal dopamine. Neuroscience 88:1153-1163.

Simon H, Taghzouti K, Le Moal M (1986). Deficits in spatialmemory tasks following lesions of septal dopaminergic terminals in the rat. Behav Brain Res 19:7-16.

Willig F, Van de Velde D, Laurent J, M'Harzi M, Delacour J (1992). The Roman strains of rats as a psychogenetic tool for pharmacological investigation of working memory: example with RU 41656. Psychopharmacology 107:415-424.

Wirtshafter D, Asin KE (1986). Discrimination learning and reversal following electrolytic lesions of the median raphe nucleus. Physiol Behav 37:213-219. 